University of Windsor

Scholarship at UWindsor

2016

\title{
Reinventing Butyl Rubber for Stretchable Electronics
}

Tricia B. Carmichael

University of Windsor

Akhil Vohra

University of Windsor

Heather L. Filiatrault

University of Windsor

Stanley Amyotte

University of Windsor

R. Stephen Carmichael

University of Windsor

See next page for additional authors

Follow this and additional works at: https://scholar.uwindsor.ca/chemistrybiochemistrypub

Part of the Materials Chemistry Commons

\section{Recommended Citation}

Carmichael, Tricia B.; Vohra, Akhil; Filiatrault, Heather L.; Amyotte, Stanley; Carmichael, R. Stephen; Suhan, Natalie D.; Conrad, Siegers; Ferrari, Lorenzo; and Davidson, Gregory J E. (2016). Reinventing Butyl Rubber for Stretchable Electronics. Advanced Functional Materials, 26 (29), 5222-5229.

https://scholar.uwindsor.ca/chemistrybiochemistrypub/86

This Article is brought to you for free and open access by the Department of Chemistry and Biochemistry at Scholarship at UWindsor. It has been accepted for inclusion in Chemistry and Biochemistry Publications by an authorized administrator of Scholarship at UWindsor. For more information, please contact scholarship@uwindsor.ca. 


\section{Authors}

Tricia B. Carmichael, Akhil Vohra, Heather L. Filiatrault, Stanley Amyotte, R. Stephen Carmichael, Natalie D. Suhan, Siegers Conrad, Lorenzo Ferrari, and Gregory J E Davidson 


\section{WILEY-VCH}

DOI: 10.1002/ ((please add manuscript number))

Article type: Full Paper

\section{Reinventing Butyl Rubber for Stretchable Electronics}

Akhil Vohra, Heather L. Filiatrault, Stanley D. Amyotte, R. Stephen Carmichael, Natalie D. Suhan, Conrad Siegers, Lorenzo Ferrari, Gregory J. E. Davidson, and Tricia Breen Carmichael*

A. Vohra, Dr. H. L. Filiatrault, S. D. Amyotte, R. S. Carmichael, Prof. T. B. Carmichael Department of Chemistry \& Biochemistry, University of Windsor, Windsor, ON, Canada, N9B 3P4

E-mail: tbcarmic@uwindsor.ca

Dr. N. D. Suhan, Dr. C. Siegers, L. Ferrari, Dr. G. J. E. Davidson

TSR Research \& Development, Lanxess, Inc., 999 Collip Circle, London, ON, Canada, N6G $4 \mathrm{XB}$

Keywords: stretchable electronics, elastomers, gas barriers, butyl rubber, PDMS

The development of stretchable electronic devices that are soft and conformable has relied heavily on a single material - polydimethylsiloxane - as the elastomeric substrate. Although polydimethylsiloxane has a number of advantageous characteristics, its high gas permeability is detrimental to stretchable devices that use materials sensitive to oxygen and water vapor, such as organic semiconductors and oxidizable metals. Failing to protect these materials from atmosphere-induced decomposition leads to premature device failure; therefore, it is imperative to develop elastomers with gas barrier properties that enable stretchable electronics with practical lifetimes. Here, we reinvent butyl rubber - a material with an intrinsically low gas permeability traditionally used in the innerliners of tires to maintain air pressure - for stretchable electronics. This new material is smooth and optically transparent, possesses the low gas permeability typical of butyl rubber, and vastly outperforms polydimethylsiloxane as an encapsulating barrier to prevent the atmospheric degradation of sensitive electronic materials and the premature failure of functioning organic devices. The merits of transparent 


\section{WILEY-VCH}

butyl rubber presented here position this material as an important counterpart to polydimethylsiloxane that will enable future generation stretchable electronics.

\section{Introduction}

Stretchable electronics research has delivered extraordinary technology demonstrations that have the potential to change the way humans interact with electronics. ${ }^{[1,2]}$ Examples include stretchable light-emitting devices, ${ }^{[3-6]}$ batteries, ${ }^{[7]}$ and solar cells ${ }^{[8]}$ wearable strain and touch sensors $;{ }^{[9,10]}$ wearable biosensors that monitor glucose levels, blood pressure and heart rate ${ }^{[11,12]}$ and soft biodevices that can be implanted into the body to study brain activity and for mapping cardiac electrophysiology. ${ }^{[13]}$ Researchers have developed a considerable diversity of strategies and materials to create stretchable functional materials that enable stretchable electronics, ${ }^{[1,2]}$ such as the design of new elastomeric composites that are conductive or emissive, ${ }^{[3,14]}$ conductive thin films adhered to elastomers, ${ }^{[15,16]}$ buckled structures that unfold when stretched, ${ }^{[17,18]}$ stretchable ionic conductors, ${ }^{[19]}$ and stretchable liquid metals. ${ }^{[20]}$ Despite this explosive growth, there is surprisingly little diversity in the elastomeric substrate used in stretchable electronics. These studies have overwhelmingly relied on a single type of elastomer: the silicone rubber polydimethylsiloxane (PDMS). There are good reasons to make PDMS the de facto choice for stretchable electronics. PDMS is optically transparent and clear; soft and stretchable; commercially available; and easy to mold. ${ }^{[21]}$ Although these properties have compelled researchers to take a "one size fits all" approach to stretchable electronics, the reality is that PDMS cannot universally fulfill all of the present and future requirements of stretchable devices. PDMS is highly permeable to oxygen and water vapor, ${ }^{[22]}$ which may be ideal for some wearable and implantable devices; however, this permeability is a detriment when the device components are air- or moisturesensitive, such as semiconducting organic molecules and polymers. The high permeability of PDMS leaves organic devices such as organic light-emitting devices (OLEDs), light-emitting electrochemical cells (LEECs), and organic photovoltaics (OPVs) vulnerable to 


\section{WILEY-VCH}

decomposition, ${ }^{[23-25]}$ which adversely affects device lifetimes and leads to premature device failure. It is critical to develop ways to protect these devices to advance the field toward stretchable electronics with practical lifetimes.

Gas-diffusion barriers are essential to organic electronics. This problem is well known for flexible organic devices fabricated on plastic substrates, in which oxygen and moisture readily permeate through the plastic into the device. Researchers have augmented the impermeability of plastics to protect flexible devices by depositing thin coatings of materials such as metal oxides or nitrides, or hybrid organic/inorganic multilayers, onto the plastic surface. ${ }^{[26-28]}$ The limited stretchability of these barrier materials, however, makes them unsuitable as gasdiffusion barrier coatings on elastomers; consequently, there are few examples of stretchable barrier films on elastomers. ${ }^{[29-32]}$ Furthermore, the basic approach of fabricating a coating to augment barrier properties adds processing steps, such as vacuum deposition or layer-by-layer self-assembly, that can be slow and expensive. Here, we present a new approach to protecting stretchable organic electronic devices that replaces PDMS with an elastomer - butyl rubber with an intrinsically low gas permeability. Butyl rubber (poly(isobutylene-co-isoprene), IIR) is a synthetic rubber made by copolymerizing $\sim 98 \%$ isobutylene with $\sim 2 \%$ isoprene, which is then compounded with fillers and stabilizing agents, and vulcanized to yield a durable end product that is both elastomeric and highly impermeable to gases and water vapor. ${ }^{[33]}$ This combination of useful properties comes from the chemical structure of IIR: Methyl groups on the polymer backbone impede the movement of the polymer chains and thus reduce the ability of gas molecules to pass through the material. ${ }^{[34]}$ The low levels of unsaturation on long polyisobutylene segments allow these chains to reconfigure themselves to distribute applied stress, and the covalent cross-links enable the material to return to its original shape after the stress is removed. ${ }^{[33]}$ Because of these properties, IIR is the traditional workhorse for applications that require airtight, elastomeric materials: in the automotive industry as the innerliners of tires, in the pharmaceutical industry as impermeable stoppers to protect 


\section{WILEY-VCH}

sterilized media, and in the sporting goods industry as bladders in inflatable balls. The IIR traditionally used in these applications, however, is no substitute for PDMS in stretchable electronics: It is opaque due to particulate fillers such as carbon black, silica, and talc, thus making it unsuitable for optoelectronic applications such as stretchable light-emitting devices and solar cells. It furthermore has a rough surface topography from standard compression molding techniques, which may limit its effectiveness as a laminated barrier or substrate for stretchable electronics. Here, we reinvent IIR to adapt it to stretchable electronics. We introduce a new formulation of IIR consisting of a peroxide-cured IIR ionomer and a new molding process to produce, for the first time, IIR sheets with high optical transparency and surface smoothness as well as the intrinsically low permeability typical of IIR. We demonstrate that this new material is an effective barrier layer to protect sensitive electronic materials and devices.

\section{Results and Discussion}

\subsection{Preparation and Molding of Transparent IIR}

Our methodology to fabricate smooth, transparent IIR (T-IIR) sheets for stretchable electronics is a modification of a typical industrial manufacturing process. Industrial processes compound a poly(isobutylene-co-isoprene) copolymer with particulate fillers, other additives, and a cross-linking agent (typically sulfur), and then mold the material into the desired shape and cure using compression, injection, or transfer molding. ${ }^{[33]}$ Our process to form T-IIR uses peroxide curing rather than sulfur vulcanization to avoid incorporating sulfur and sulfur by-products in the rubber that can cause blooming or discoloration. ${ }^{[35]}$ Organic peroxides are known to cleave isobutylene-rich copolymers to cause fragmentation and molecular weight reduction rather than cross-linking; ${ }^{[36]}$ we avoided this problem by reacting a commercial brominated IIR (Bromobutyl 2030, which has $0.8-1.5 \mathrm{~mol} \%$ isoprene) with the phosphorus-based nucleophile diphenylphosphinostyrene (DPPS) to generate an IIR ionomer with pendant vinyl sites (BB2030-DPPS) (Figure 1a) that preferentially undergo free radical 


\section{WILEY-VCH}

oligomerization to crosslink the material. ${ }^{[36,37]}$ We compounded BB2030-DPPS with peroxide and then used compression molding at $175{ }^{\circ} \mathrm{C}$ to create cross-linked T-IIR rubber sheets. Our molding process produced $45-\mathrm{cm}^{2} \mathrm{~T}$-IIR sheets with a thickness of $0.5 \mathrm{~mm}$; these dimensions can be easily modified by changing the mold dimensions. The mechanical properties of T-IIR elastomer are similar to those of PDMS, with a slightly lower Young's modulus (0.41 MPa for T-IIR vs 2.05 MPa for PDMS) (Table S1). ${ }^{[38]}$

High optical transparency is a key metric to enable the use of T-IIR in stretchable optoelectronics. Although T-IIR does not contain particulate fillers and is thus a transparent material, standard methods of compression molding produce T-IIR sheets with a high surface roughness, which diminishes the percentage of transmitted light due to scattering. For example, compression molding T-IIR between two Teflon sheets enables the easy release of T-IIR, but the high root-mean-square (RMS) surface roughness of $167.5 \pm 2.9 \mathrm{~nm}$ (Figure S1a) imparted to the T-IIR sheet from the Teflon during the molding process results in a $\%$ transmittance of only $15 \%$ at $550 \mathrm{~nm}$ (Figure $1 \mathrm{~b}$ ). On the other hand, replacing the Teflon sheets with highly smooth silicon wafers or glass plates treated with a fluorinated silane release layer results in sticking of the molded T-IIR to the silicon or glass surfaces, making separation of the T-IIR from the mold difficult and damaging the T-IIR surfaces (Figure S1b). We therefore designed a compression mold with smooth surfaces that, at the same time, released the cured T-IIR without sticking. We coated an aluminum sheet with a thin layer ( $25 \mu \mathrm{m})$ of PDMS by spin-coating. Although the aluminum surface is rough (RMS roughness $=50.1 \pm 13.4 \mathrm{~nm}$, Figure S1c), spin-coating PDMS on the surface fills in the rough topography to produce a smooth PDMS surface (RMS roughness $=1.5 \pm 0.3 \mathrm{~nm}$, Figure $\mathrm{S} 1 \mathrm{~d})$ with the typical low surface free energy of PDMS. ${ }^{[21]}$ Compression molding T-IIR against PDMS-coated aluminum produces smooth T-IIR (Figure 1c, RMS roughness $=3.9 \pm 0.6 \mathrm{~nm}$ ) that separates easily from the mold. This surface smoothness corresponds to $80 \%$ 


\section{WILEY-VCH}

transmittance at a wavelength of $550 \mathrm{~nm}$ (Figure 1b); the photograph in Figure 1d demonstrates the clarity of molded T-IIR. In comparison, PDMS sheets formed using a standard method of curing against the smooth surface of a polystyrene Petri dish have similar surface smoothness $(\mathrm{RMS}$ roughness $=1.4 \pm 0.3 \mathrm{~nm})$ but are more transparent $(100 \%$ at 550 $\mathrm{nm})$. The lower $\%$ transmittance of T-IIR can be attributed to the slightly yellow color that results from the heat history of the product. The biggest difference between T-IIR and PDMS, however, is gas permeability. We measured oxygen permeation through T-IIR and PDMS, and found that the permeability of T-IIR $\left(216 \pm 3 \mathrm{cc}-\mathrm{mm} / \mathrm{m}^{2}\right.$-day-atm $)$ is an order of magnitude lower than that of the best-performing PDMS sample (4500 cc-mm/ $/ \mathrm{m}^{2}$-day-atm).

\subsection{T-IIR as a Gas-Diffusion Barrier for Organic Electronic Materials and Devices}

The lower gas permeability of T-IIR compared to that of PDMS can be exploited to protect organic electronic materials from atmospheric degradation. We compared the protective capabilities of T-IIR and PDMS as laminated encapsulants for passive films of the methylammonium lead mixed-halide perovskite $\mathrm{CH}_{3} \mathrm{NH}_{3} \mathrm{PbI}_{3-\mathrm{x}} \mathrm{Cl}_{\mathrm{x}}$, an absorber material used in solar cells. This perovskite material provides high power conversion efficiencies (> $20 \%) ;{ }^{[39]}$ however, it decomposes when exposed to moisture and heat, which hinders its potential use in commercial solar cells. ${ }^{[40,41]}$ Pristine perovskite films on glass prepared in an inert, dry atmosphere show a strong characteristic absorption of the $\mathrm{CH}_{3} \mathrm{NH}_{3} \mathrm{PbI}_{3-\mathrm{x}} \mathrm{Cl}_{\mathrm{x}}$ perovskite structure in the visible region of 750 to $450 \mathrm{~nm}$ of the UV-vis absorption spectrum (Figure 2a). ${ }^{[40]}$ To compare the barrier properties of PDMS and T-IIR, we laminated sheets of T-IIR and PDMS over the surfaces of pristine perovskite films on glass to create TIIR/perovskite/glass and PDMS/perovskite/glass structures. We heated these structures, along with a bare perovskite film as a control, to $75^{\circ} \mathrm{C}$ at $100 \%$ relative humidity (RH) in a controlled chamber and then characterized the films using UV-vis spectroscopy. It was necessary to peel away the T-IIR film after treatment to avoid the contribution of the T-IIR absorption at $350-450 \mathrm{~nm}$ (Figure S2) to the UV-vis spectrum of the perovskite. After $24 \mathrm{~h}$ 


\section{WILEY-VCH}

of treatment, the characteristic absorption of the perovskite material of the bare and PDMSlaminated films disappeared (Figure 2a) with a concomitant change in the color of the films from dark brown to yellow. Previous studies have demonstrated that water molecules infiltrate the perovskite crystal structure to hydrogen bond to the methylammonium cations and cause bond dissociation within the crystal, leaving behind a residual layer of yellow lead iodide. ${ }^{[40]}$ Since the glass substrate is impermeable, it is clear that water molecules readily permeated through the PDMS encapsulation. In contrast, the impermeability of T-IIR protected the perovskite films from moisture incursion. These films retained the color and characteristic absorption of undamaged perovskite (Figure 2a). The small decrease in absorption intensity likely resulted from the inadvertent loss of perovskite material from the film when T-IIR layer was removed to collect the absorption spectrum. Support for this reasoning comes from spectra collected after $48 \mathrm{~h}$ of heat and humidity treatment, which showed no further loss compared to 24 hours of treatment.

T-IIR is not only more effective than PDMS at protecting sensitive compounds from atmospheric degradation, it also is more effective at preserving energized organic electronic materials in functioning organic light-emitting devices. We used LEECs based on an ionic ruthenium emissive complex for this demonstration due to the sensitivity of these devices to moisture. ${ }^{[2]}$ LEECs are architecturally simple, three-layer devices that sandwich an emissive material consisting of a mixture of ionic and electronic conductors between two electrodes. ${ }^{[42,43]}$ The simplicity of the LEEC architecture has enabled intrinsically stretchable devices. $^{[3-5]}$ The emissive material can be a semiconducting polymer blended with a solid electrolyte that provides mobile ions, ${ }^{[43]}$ or an ionic transition metal complex such as Ru(dtbbpy $)_{3}\left(\mathrm{PF}_{6}\right)_{2}$, which is both an electronic and ionic conductor. ${ }^{[42]}$ Application of a voltage causes the migration of ions in the emissive material to the electrodes, producing high electric fields at these interfaces and lowering the barrier to charge injection. ${ }^{[44]}$ For this reason, LEECs do not require a low work function, air-sensitive metal as the cathode, unlike OLEDs. 


\section{WILEY-VCH}

The moisture sensitivity of Ru-based LEECs comes from the ruthenium complex itself: Rubased LEECs exhibit irreversible photoluminescence decay due to a quenching species - an oxo bridged dimer with two coordinated water molecules - that forms during device operation in ambient conditions. ${ }^{[24]}$ We fabricated LEECs under inert conditions in a glove box by spincoating a solution of $\mathrm{Ru}(\mathrm{dtb}-\mathrm{bpy})_{3}\left(\mathrm{PF}_{6}\right)_{2}$ and polymethylmethacrylate (PMMA) onto patterned ITO electrodes on glass, and then deposited gold top contacts by e-beam evaporation through a shadow mask (Figure S3). We encapsulated the devices by laminating sheets of T-IIR and PDMS over the surface (Figure $2 \mathrm{~b}$ ). The device characteristics of encapsulated LEECs were similar to those of LEECs without encapsulation when the devices were tested in an inert atmosphere, with maximum radiance of $\sim 3 \mu \mathrm{W}$ and external quantum efficiencies (EQEs) of $\sim 0.03 \%$ (Table 1 and Table S2; Figure 2c, d; Figure S4). The application of a constant dc voltage causes an initial peak dc current response due to charge flow, followed by a slow, continuous downward trend that defines the lifetime of the device. Radiance typically follows the trend of the current curve. We then exposed encapsulated devices to $100 \% \mathrm{RH}$ at room temperature for $3 \mathrm{~h}$. Water vapor permeation through the PDMS layer irreversibly damaged the devices: Application of a voltage did not result in the characteristic current curves and slow downward decay typical of undamaged devices; rather, a series of sporadic charging and discharging events occurred, evidenced by low-intensity, short-lived radiance surges (Figure 2c). The EQE dropped by a factor of $>1000$. In contrast, T-IIR protected the devices from moisture incursion, maintaining a high device yield (90\%) and device characteristics that were unchanged from devices tested in an inert atmosphere (Table 1, Figure 2d).

\subsection{T-IIR as a Gas-Diffusion Barrier to Metal Corrosion}

Stretchable electronic devices often use gold films as device interconnects and contacts. Although freestanding gold films typically fracture at a few percent tensile strain, depositing thin gold films on the surface of PDMS suppresses the strain localization that causes necking and rupture, enabling the film to remain conductive with stretching. ${ }^{[15,45]}$ Configuring the 


\section{WILEY-VCH}

metal film into serpentine patterns or out-of-plane structures increase the elongation at electrical failure to enable highly stretchable electronics. ${ }^{[16,46,47]}$ Stretchable electronics has relied on gold as the metal of choice because it is chemically inert and not easily oxidized, thus its conductivity remains stable even in high humidity or corrosive environments. ${ }^{[48]}$ However, an important motivation for stretchable electronics is the development of low-cost, lightweight electronics that can be deployed seamlessly in everyday life. A necessity for this vision of ubiquitous electronics is the replacement of gold with less costly and more abundant metals such as copper or silver; however, these metals readily corrode in atmospheric conditions by processes that are sensitive to environmental factors such as temperature, humidity, and the presence of ubiquitous pollutants. ${ }^{[49]}$ We compared the ability of T-IIR and PDMS to protect films of silver and copper from corrosion by laminating T-IIR and PDMS over the surfaces of 250 - $\AA$-thick copper and silver films patterned into 1-mm-wide wires on glass, and then exposing the structures to $100 \% \mathrm{RH}$ to accelerate the corrosion. ${ }^{[49]}$ After 7 days of exposure, optical micrographs of the copper and silver thin-film wires encapsulated using PDMS revealed a patina consistent with corrosion (Figure 3b, e), whereas wires encapsulated using T-IIR appeared unchanged from the original, unexposed films (Figure $3 \mathrm{a}$, $\mathrm{c}, \mathrm{d}, \mathrm{f}$ ). We quantified the effect of corrosion by measuring the resistance of copper and silver thin-film wires encapsulated with PDMS and T-IIR at 24-hour intervals of exposure to 100\% $\mathrm{RH}$, and plotting the ratio of the measured resistance to the initial resistance $\left(\mathrm{R} / \mathrm{R}_{0}\right)$ versus time in days (Figure 3g, h). Copper and silver films encapsulated with PDMS became nonconductive after periods ranging from $5-9$ days. The resistance of the best samples increased abruptly after 8 days, and became essentially infinite thereafter (Figure $3 \mathrm{~g}, \mathrm{~h}$, insets). In contrast, T-IIR was substantially more effective at protecting the metal films from corrosion: $\mathrm{R} / \mathrm{R}_{0}$ of copper films remained $<2.2$ after 150 days; for silver, $\mathrm{R} / \mathrm{R}_{0}$ was $<1.2$ after 360 days (Figure $3 \mathrm{~g}, \mathrm{~h}$ ). We further illustrated the protective abilities of T-IIR by constructing circuits on glass consisting of an LED in series with two silver thin-film wires, 


\section{WILEY-VCH}

laminating the surfaces with either PDMS or T-IIR, and exposing the laminated circuits to $100 \% \mathrm{RH}$. The circuit initially demonstrates a total voltage drop $\left(\mathrm{V}_{\mathrm{T}}\right)$ of $1.9 \pm 0.1 \mathrm{~V}$ when biased with a current of $1 \mathrm{~mA}$. We measured $\mathrm{V}_{\mathrm{T}}$ of the circuits after 24-hour intervals of exposure to $100 \% \mathrm{RH}$ (Figure $3 \mathrm{i}$ ). $\mathrm{V}_{\mathrm{T}}$ for the best-performing PDMS-encapsulated sample increased to $40 \mathrm{~V}$ after 10 days, which indicates that corrosion of the silver wires increased the resistance of the circuit and thus $\mathrm{V}_{\mathrm{T}}$. In contrast, $\mathrm{V}_{\mathrm{T}}$ for circuits encapsulated with T-IIR was $2.5 \mathrm{~V}$ after 10 days, and remained $<5 \mathrm{~V}$ even after 20 days. We tested the protective abilities of T-IIR using more forcing environmental conditions by fully immersing circuits laminated with PDMS and T-IIR under water. The LEDs of PDMS-laminated circuits failed to emit light after 9 hours of immersion, whereas T-IIR protected circuits from water-induced failure for $>180$ hours.

We used an extremely corrosive environment to challenge the superior barrier properties of T-IIR compared to those of PDMS. We used films of silver nanowires (AgNWs) as the passive sensor for this testing. Transparent and conductive AgNW films are leading candidates to replace the standard transparent conductor, indium tin oxide (ITO), as transparent electrodes in optoelectronic devices. AgNW films deposited from solution using low-cost methods such as drop casting or spray coating produce films with conductivities and transparencies that rival or surpass those of ITO ${ }^{[50]}$ Furthermore, AgNW films deposited on elastomers possess good stretchability, and thus have been used as transparent conducting electrodes in stretchable light-emitting devices and solar cells..$^{[5,8,51]}$ To stress test T-IIR encapsulation layers, we formed AgNW films onto glass substrates by simply drop casting AgNW suspensions in ethanol. These AgNW films consist of a uniform distribution of AgNWs on the surface, exhibit a signature absorbance peak at $365 \mathrm{~nm},{ }^{[52]}$ and have a sheet resistance of $10.8 \pm 2.4 \Omega /$ sq (Figure 4a, b). We laminated T-IIR and PDMS over these films to create T-IIR/AgNW/glass and PDMS/AgNW/glass structures, which we then exposed to the corrosive vapor of nitric acid in a closed container for $12 \mathrm{~h}$. AgNW films encapsulated 


\section{WILEY-VCH}

with PDMS were no better than unprotected films after the vapor treatment: Neither unprotected nor PDMS-protected films exhibited the characteristic absorption at $365 \mathrm{~nm}$ (Figure 4a), and the films were no longer conductive. Optical microscopy revealed that nitric acid vapor permeation through the PDMS etched the AgNW film, destroying the structure of the AgNWs and eliminating the percolation pathways through the film (Figure 4c). In contrast, T-IIR protected AgNW films from such damage: The transmittance spectrum, film morphology, and sheet resistance $(13.2 \pm 1.8 \Omega / \mathrm{sq})$ all remained essentially unchanged after vapor treatment (Figure 4a, d). We challenged the barrier properties of T-IIR even further by replacing the impermeable glass substrate with T-IIR to create the sandwich structure TIIR/AgNW/T-IIR. Nonetheless, the sheet resistance and film morphology remained unchanged after exposure to nitric acid vapor for $12 \mathrm{~h}$ (Figure S5).

\section{Conclusions}

Since its discovery in 1937 , butyl rubber has been a ubiquitous elastomer in everyday applications that require airtight, stretchable materials. In this paper, we have reported the first example of transparent butyl rubber produced by molding a new, filler-free, and peroxide-curable IIR formulation. We have furthermore shown that this new material has a potentially revolutionary role to play in technology due to its combination of high gas impermeability, stretchability, and optical transparency and clarity. We have presented demonstrations to clearly illustrate that T-IIR is a far more effective barrier to moisture, oxygen, and even corrosive vapors than PDMS. T-IIR and PDMS thus have complementary roles to play in the field of stretchable electronics: T-IIR protects electronic materials and devices from moisture, oxygen, and corrosive vapors; therefore, it may enable stretchable devices built using sensitive organic materials or readily-oxidized metals, such as OLEDs and OPVs, to reach practical lifetimes. In contrast, PDMS is a highly permeable layer that is better suited to applications requiring breathability, such as skin-mounted and bioimplantable electronics. 


\section{WILEY-VCH}

\section{Experimental Section}

Bromobutyl 2030 was obtained from LANXESS, Inc. Poly(dimethylsiloxane) (PDMS) (Sylgard 184) was obtained from Dow Corning, Midland, MI. Aluminum sheets (3003 series) were obtained from Essex Metals, ON, Canada. All other chemicals were obtained from commercial sources and used as received.

Preparation of Compression Molding Surfaces: $7.0 \mathrm{~cm} \times 6.5 \mathrm{~cm}$ aluminum sheets $(0.6 \mathrm{~mm}$ thick) were cleaned by swabbing with acetone and isopropanol, followed by oxidation in a UV ozone cleaner for 5 min. PDMS prepolymer was then spin-coated on the aluminum surface in step speeds of $1500 \mathrm{rpm}$ for $20 \mathrm{~s}$ and $2500 \mathrm{rpm}$ for $30 \mathrm{~s}$, followed by curing in a 60 ${ }^{\circ} \mathrm{C}$ oven for $1 \mathrm{~h}$.

T-IIR Compounding and Molding: $100 \mathrm{~g}$ Bromobutyl 2030 was added to a Brabender internal mixer equipped with high shear (roller) blades at $60{ }^{\circ} \mathrm{C}$ and $60 \mathrm{rpm}$. The rubber was masticated alone for $60 \mathrm{~s}$, followed by addition of $5 \mathrm{~g}$ DPPS. After an additional $4 \mathrm{~min}$ of mixing, 0.3 g peroxide (Trigonox 101-45B-PD-AM, Akso Nobel) was added. After 6 min of mixing, $10 \mathrm{~g}$ of the compound was placed in the mold between the molding masters spaced to provide T-IIR sheets with $\sim 0.5 \mathrm{~mm}$ thickness. The mold was placed in a manual Carver press with the platens set to $175^{\circ} \mathrm{C}$ under 20 tons of pressure, and cured for $8 \mathrm{~min}$.

Barrier Studies: PDMS and T-IIR barriers were laminated on top of films of the organicinorganic perovskite $\mathrm{CH}_{3} \mathrm{NH}_{3} \mathrm{PbI}_{3-\mathrm{x}} \mathrm{Cl}_{\mathrm{x}}$, light-emitting electrochemical cells (LEECs), 250- $\AA$ thick films of copper and silver on glass, and films of AgNWs. The encapsulated films and devices were exposed to humid air (perovskite films and LEECs), and nitric acid vapor (AgNW films), and then compared using characterization techniques. Detailed information on film and device preparation and characterization methodology is provided in the supporting information.

Characterization: AFM images were obtained using a Digital Instruments Multimode atomic force microscope in tapping mode. The measurements were carried out using Veeco 


\section{WILEY-VCH}

type FESP cantilever with a nominal tip radius of $8 \mathrm{~nm}$ and a nominal force constant of 2.8

$\mathrm{N} / \mathrm{m}$. AFM images were collected over a $13 \mu \mathrm{m}$ x $13 \mu \mathrm{m}$ scan area using a scan rate of 0.5

$\mathrm{Hz}$ and a scanning resolution of 512 samples/line. RMS roughness values from three different areas of a sample were averaged. Stress/strain properties were tested using a T2000 tensile tester and the ASTM D412 procedure; reported values are the median of three measurements. Hardness was tested using a Shore A Hardness Tester according to ASTM D2240; reported values are the median of five measurements. Permeability was measured using a Mocon OxTran Model 2/61 permeation test system. The thickness of the samples was measured at five points, and samples were discarded if thickness differences between any of these five points differed by $>25 \%$. The samples were preconditioned with oxygen for $10 \mathrm{~h}$ in the instrument prior to permeation measurements. Oxygen permeation was measured at $40{ }^{\circ} \mathrm{C}$ and $0 \%$ relative humidity over 3 - 5 cycles of 20 min each to determine the permeability (in cc$\mathrm{mm} / \mathrm{m}^{2}$-day). The high permeability of PDMS to oxygen gas swamped the detector; the reported permeability is for the best sample (i.e., the lowest permeability value we measured). Transmittance and absorption spectra were measured using a Varian Cary 50 UV-Visible Spectrophotometer.

\section{Supporting Information}

Supporting Information is available from the Wiley Online Library or from the author.

\section{Acknowledgements}

This research was supported by the National Sciences and Engineering Research Council of Canada (NSERC) and LANXESS, Inc. We thank Dr. Mark Biesinger at Surface Science Western for X-ray photoelectron spectroscopy.

Received: ((will be filled in by the editorial staff))

Revised: ((will be filled in by the editorial staff)) Published online: ((will be filled in by the editorial staff))

[1] T. Sekitani, T. Someya, Adv. Mater. 2010, 22, 2228.

[2] J. A. Rogers, T. Someya, Y. Huang, Science 2010, 327, 1603. 


\section{WILEY-VCH}

[3] H. L. Filiatrault, G. C. Porteous, R. S. Carmichael, G. J. E. Davidson, T. B. Carmichael, Adv. Mater. 2012, 24, 2673.

[4] Z. Yu, X. Niu, Z. Liu, Q. Pei, Adv. Mater. 2011, 23, 3989.

[5] J. Liang, L. Li, X. Niu, Z. Yu, Q. Pei, Nature Photon. 2013, 7, 817.

[6] J. Wang, C. Yan, K. J. Chee, P. S. Lee, Adv. Mater. 2015, 27, 2876.

[7] K. Xie, B. Wei, Adv. Mater. 2014, 26, 3592.

[8] D. J. Lipomi, Z. Bao, Energy Environ. Sci. 2011, 4, 3314.

[9] M. L. Hammock, A. Chortos, B. Tee, J. Tok, Z. Bao, Adv. Mater. 2013, 25, 5996.

[10] S. Bauer, S. Bauer-Gogonea, I. Graz, M. Kaltenbrunner, C. Keplinger, R. Schwödiauer, Adv. Mater. 2014, 26, 149.

[11] X. Huang, Y. Liu, H. Cheng, W. -J. Shin, J. A. Fan, Z. Liu, C. -J. Lu, G. -W. Kong, K. Chen, D. Patnaik, S. -H. Lee, S. Hage-Ali, Y. Huang, J. A. Rogers, Adv. Funct. Mater. 2014, 24, 3846 .

[12] D. -H. Kim, N. Lu, R. Ma, Y. -S. Kim, R. -H. Kim, S. Wang, J. Wu, S. M. Won, H. Tao, A. Islam, K. J. Yu, T. -I. Kim, R. Chowdhury, M. Ying, L. Xu, M. Li, H.-J. Chung, H. Keum, M. McCormick, P. Liu, Y. -W. Zhang, F. G. Omenetto, Y. Huang, T. Coleman, J. A. Rogers, Science 2011, 333, 838.

[13] D. -H. Kim, R. Ghaffari, N. Lu, J. A. Rogers, Annu. Rev. Biomed. Eng. 2012, 14, 113.

[14] T. Sekitani, H. Nakajima, H. Maeda, T. Fukushima, T. Aida, K. Hata, T. Someya, Nature Mater. 2009, 8, 494.

[15] S. P. Lacour, S. Wagner, Z. Huang, Z. Suo, Appl. Phys. Lett. 2003,82, 2404.

[16] H. L. Filiatrault, R. S. Carmichael, R. A. Boutette, T. B. Carmichael, ACS Appl. Mater. Interfaces 2015, 7, 20745.

[17] D. -Y. Khang, J. A. Rogers, H. H. Lee, Adv. Funct. Mater. 2008, $18,1$. 


\section{WILEY-VCH}

[18] Y. Zhang, Z. Yan, K. Nan, D. Xiao, Y. Liu, H. Luan, H. Fu, X. Wang, Q. Yang, J. Wang, W. Ren, H. Si, F. Liu, L. Yang, H. Li, J. Wang, X. Guo, H. Luo, L. Wang, Y. Huang, J. A. Rogers, Proc. Natl. Acad. Sci. 2015, 112, 11757.

[19] C. Keplinger, J. -Y. Sun, C. C. Foo, P. Rothemund, G. M. Whitesides, Z. Suo, Science 2013, 341, 984 .

[20] M. D. Dickey, ACS Appl. Mater. Interfaces 2014, 6, 18369.

[21] J. E. Mark, D. W. Schaefer, G. Lin, The Polysiloxanes, Oxford University Press, New York 2015.

[22] T. Aoki, Prog. Polym. Sci. 1999, 24, 951.

[23] S. Scholz, D. Kondakov, B. Lüssem, K. Leo, Chem. Rev. 2015, 115, 8449.

[24] L. J. Soltzberg, J. D. Slinker, S. Flores-Torres, D. A. Bernards, G. G. Malliaras, H. D. Abruña, J. -S. Kim, R. H. Friend, M. D. Kaplan, V. Goldberg, J. Am. Chem. Soc. 2006, 128, 7761.

[25] J. A. Hauch, P. Schilinsky, S. A. Choulis, S. Rajoelson, C. J. Brabec, Appl. Phys. Lett. 2008, 93, 103306.

[26] J. Lewis, Mater. Today 2006, 9, 38.

[27] J. Meyer, P. Görrn, F. Bertram, S. Hamwi, T. Winkler, H. -H. Johannes, T. Weimann, P. Hinze, T. Riedl, W. Kowalsky, Adv. Mater. 2009, 21, 1845.

[28] P. E. Burrows, G. L. Graff, M. E. Gross, P. M. Martin, M. K. Shi, M. Hall, E. Mast, C. Bonham, W. Bennett, M. B. Sullivan, Displays 2001, 22, 65.

[29] K. M. Holder, B. R. Spears, M. E. Huff, M. A. Priolo, E. Harth, J. C. Grunlan, Macromolecular Rapid Commun. 2014, 35, 960.

[30] F. Xiang, S. M. Ward, T. M. Givens, J. C. Grunlan, ACS Macro Lett. 2014, 3, 1055.

[31] F. Xiang, S. M. Ward, T. M. Givens, J. C. Grunlan, Soft Matter 2015, 11, 1001.

[32] F. Xiang, T. M. Givens, S. M. Ward, J. C. Grunlan, ACS Appl. Mater. Interfaces 2015, 7, 16148 . 


\section{WILEY-VCH}

[33] M. Morton, Rubber Technology 3rd Ed., Springer, Dordrecht, Netherlands 1987.

[34] Y. Iyengar, J. Polym. Sci. B: Polym. Lett. 1965, 3, 663.

[35] A. S. Kuzminskii, L. S. Feldstein, S. A. Reitlinger, Rubber Chem. Technol. 1962, 35, 147.

[36] S. Xiao, J. S. Parent, R. A. Whitney, L. K. Knight, J. Polym. Sci. A: Polym. Chem. 2010, 48, 4691.

[37] G. J. E. Davidson, D. K. Adkinson, S. M. Malmberg, L. Ferrari, C. Siegers, S. J. Chadder, (Lanxess Inc.) WO2012/083419 A1, 2012.

[38] I. D. Johnston, D. K. McCluskey, C. K. L. Tan, M. C. Tracey, J. Micromech. Microeng. 2014, 24, 035017.

[39] N. -G. Park, Mater. Today 2015, 18, 65.

[40] S. N. Habisreutinger, T. Leijtens, G. E. Eperon, S. D. Stranks, R. J. Nicholas, H. J. Snaith, Nano Lett. 2014, 14, 5561.

[41] J. Yang, B. D. Siempelkamp, D. Liu, T. L. Kelly, ACS Nano 2015, 9, 1955.

[42] J. D. Slinker, J. Rivnay, J. S. Moskowitz, J. B. Parker, S. Bernard, H. D. Abruña, G. G. Malliaras, J. Mater. Chem. 2007, 17, 2976.

[43] Q. Pei, G. Yu, C. Zhang, Y. Yang, A. J. Heeger, Science 1995, 269, 1086.

[44] S. B. Meier, D. Tordera, A. Pertegás, C. Roldán-Carmona, E. Orti, H. J. Bolink, Mater. Today 2014, 17, 217.

[45] O. Grandejus, P. Gorrn, S. Wagner, ACS Appl. Mater. Interfaces 2010, 2, 1927.

[46] P. Gorrn, W. Cao, S. Wagner, Soft Matter 2011, 7, 7177.

[47] D. Brosteaux, F. Axisa, M. Gonzalez, J. Vanfleteren, IEEE Electron Device Lett. 2007, 28,552 .

[48] S. Krech, J. R. McNeill, C. Merchant, Encyclopedia of World Environmental History Vol. 3 (Routledge, London, 2004).

[49] S. P. Sharma, J. Electrochem. Soc. 1978, 125, 2005. 


\section{WILEY-VCH}

[50] D. Langley, G. Giusti, C. Mayousse, C. Celle, D. Bellet, J. -P. Simonato, Nanotechnology 2013, 24, 452001.

[51] J. Liang, L. Li, K. Tong, Z. Ren, W. Hu, X. Niu, Y. Chen, Q. Pei, ACS Nano 2014, 8, 1590.

[52] N. Weiß, L. Müller-Meskamp, F. Selzer, L. Bormann, A. Eychmüller, K. Leo, N. Gaponik, RSC Advances 2015, 5, 19659.
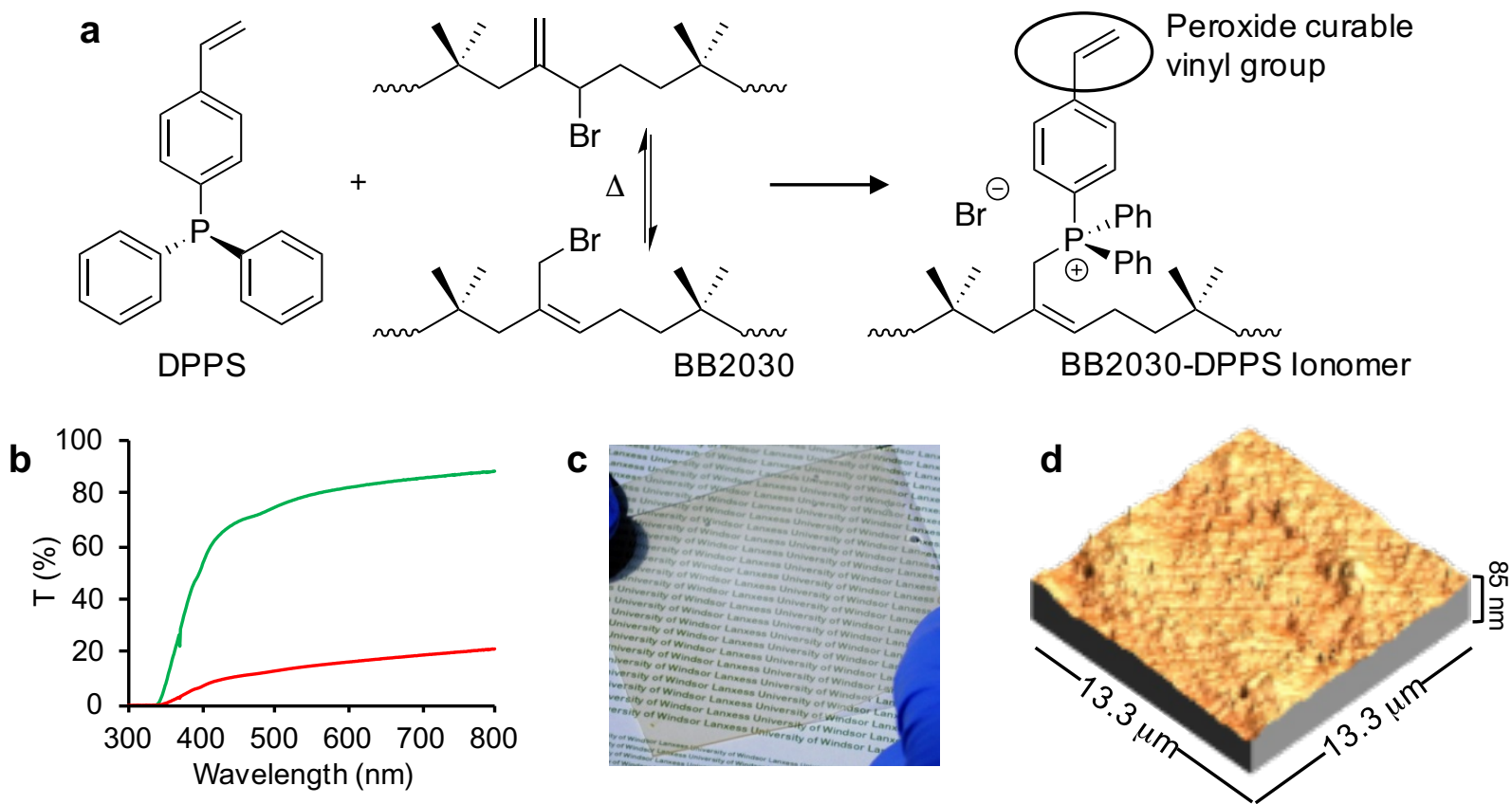

Figure 1. Preparation and characterization of T-IIR. a Synthesis of BB2030-DPPS ionomer.

b Transmission spectra of T-IIR molded against Teflon (red line) and PDMS-coated Al (green line). c Photograph of T-IIR sheet molded against PDMS-coated Al. d AFM topographic image of T-IIR molded against PDMS-coated Al. 
a

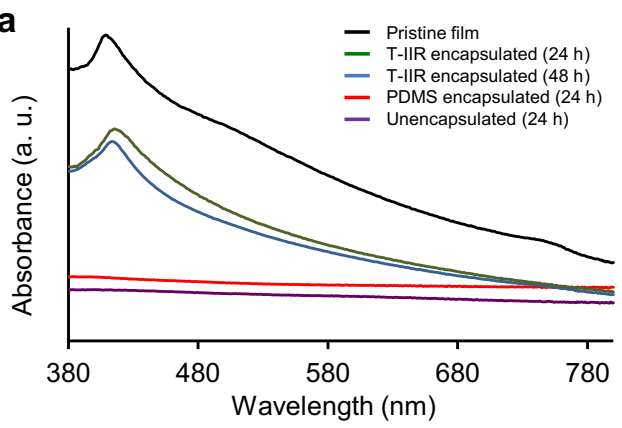

C

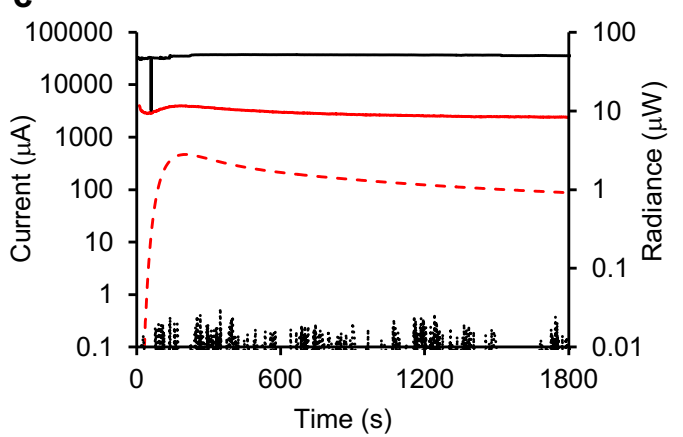

b

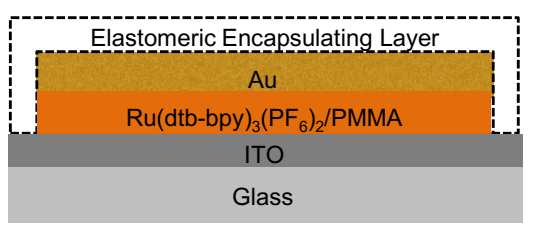

d

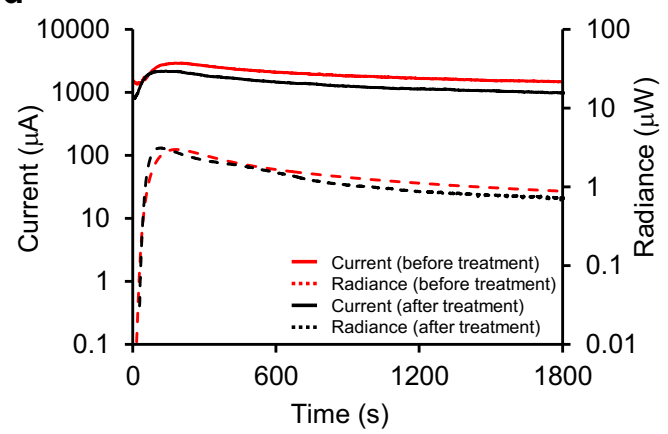

Figure 2. T-IIR as a gas-diffusion barrier for organic electronic materials and devices. a $\mathrm{UV}$-vis absorption spectra of mixed-halide perovskite films on glass. Films heated to $75^{\circ} \mathrm{C}$ at 100\% RH: T-IIR-encapsulated film treated for $24 \mathrm{~h}$ (green line) and $48 \mathrm{~h}$ (blue line); PDMS-encapsulated film treated for $24 \mathrm{~h}$ (red line); film without encapsulation treated for 24 h (purple line). Pristine, untreated perovskite film (black line). b Diagram of encapsulated LEEC (layer thicknesses not to scale). c, $\mathbf{d}$ Evolution of current (solid line) and radiance (dashed line) response before (red lines) and after (black lines) humidity treatment for LEECs encapsulated with (c) PDMS and (d) T-IIR. 


\section{WILEY-VCH}

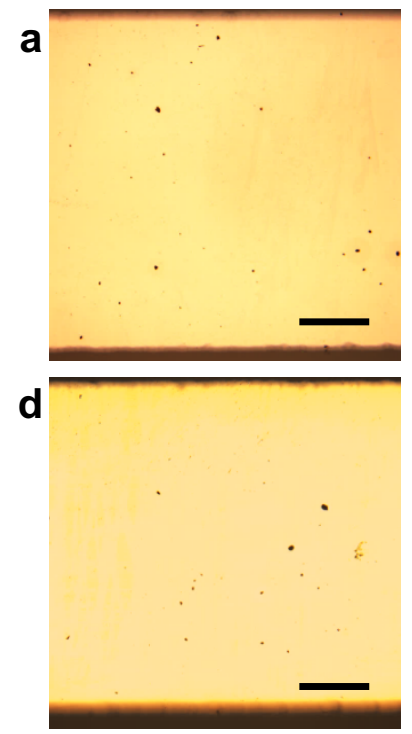

g
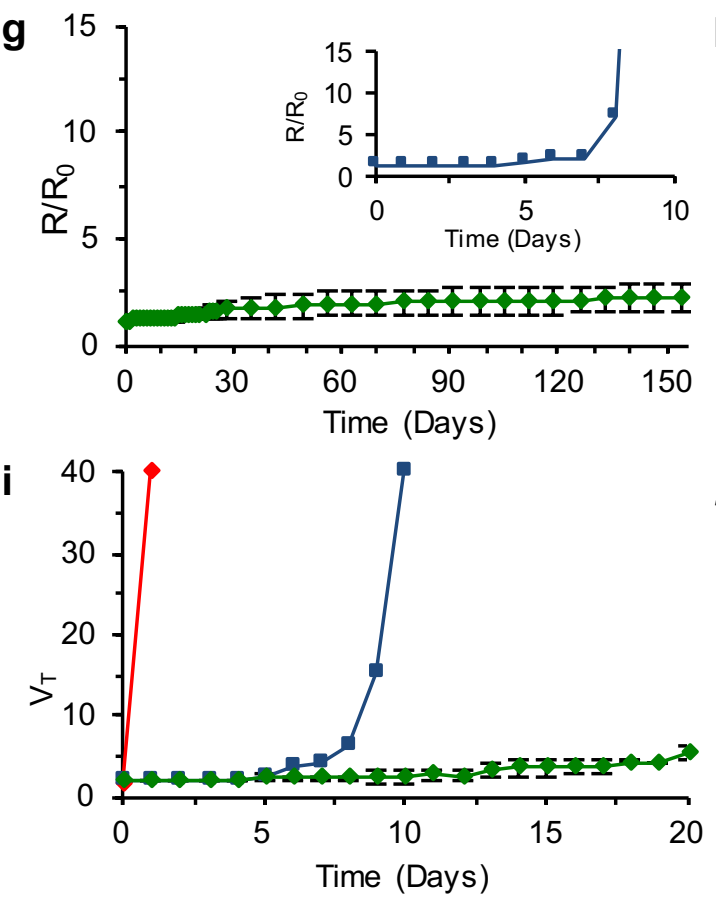

e
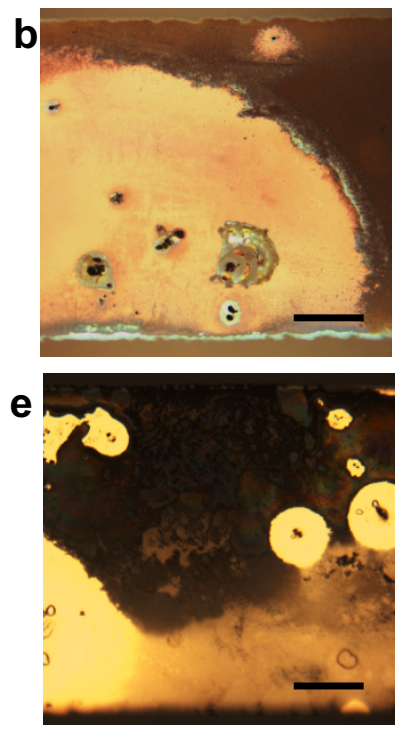

h 15

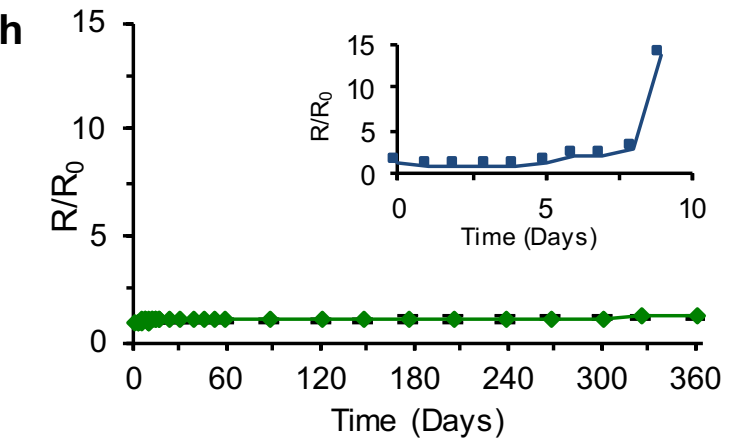

j

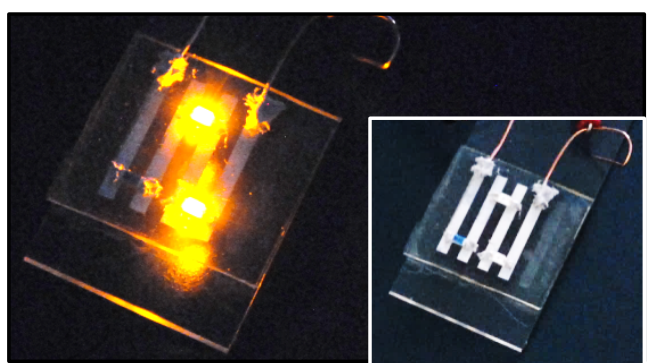

Figure 3. T-IIR as a gas-diffusion barrier to metal corrosion. a-f Optical micrographs (scale bars $=200 \mu \mathrm{m}$ ) of 250 - $\AA$-thick (a) copper and (d) silver films on glass before treatment with $100 \% \mathrm{RH}$; (b) copper and (e) silver films encapsulated with PDMS and exposed to $100 \% \mathrm{RH}$ for 7 days; (c) copper and (f) silver films encapsulated with T-IIR and exposed to $100 \% \mathrm{RH}$ for 7 days. $\mathbf{g}, \mathbf{h}$ Plots of resistance change versus time for (g) copper and (h) silver films encapsulated with T-IIR and PDMS (inset), and treated with 100\% RH. i Plot of voltage drop across LED circuits treated with $100 \%$ RH with a PDMS (blue line) and T-IIR (green line) 


\section{WILEY-VCH}

encapsulating layer. j Photograph of LED circuit with T-IIR encapsulating layer before (inset) and after 180 hours of immersion in water.
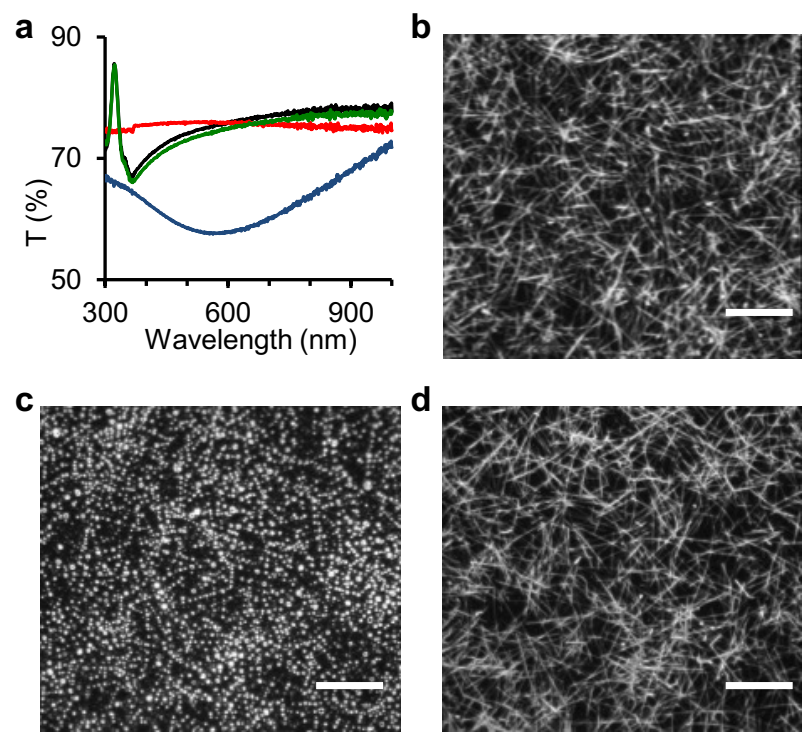

Figure 4. T-IIR as a barrier to corrosive nitric acid vapor. a, UV-vis transmittance spectra of AgNW films before exposure to nitric acid vapor (black line), and after $12 \mathrm{~h}$ exposure to nitric acid vapor with no encapsulating layer (blue line), with a T-IIR encapsulating layer (green line), and with a PDMS encapsulating layer (red line). b-d, Optical microscope images of AgNW films on glass (scale bars $=40 \mu \mathrm{m})(\mathbf{b})$ prior to nitric acid vapor exposure, (c) with a laminated PDMS barrier and exposed to nitric acid vapor for $12 \mathrm{~h},(\mathbf{d})$ with a laminated T-IIR barrier and exposed to nitric acid vapor for $12 \mathrm{~h}$. 


\section{WILEY-VCH}

Table 1. Characteristics of LEECs encapsulated with T-IIR and PDMS before and after humidity exposure.

\begin{tabular}{lcccc}
\cline { 2 - 5 } & \multicolumn{2}{c}{ T-IIR Encapsulated Devices } & \multicolumn{2}{c}{ PDMS Encapsulated Devices } \\
\cline { 2 - 5 } & Before exposure & After exposure & Before exposure & After exposure \\
\hline Average maximum radiance $(\mu \mathrm{W})$ & $2.53 \pm 0.23$ & $2.71 \pm 0.68$ & $2.88 \pm 0.16$ & $0.04 \pm 0.02$ \\
Average current $(\mathrm{mA})$ & $1.46 \pm 0.48$ & $1.57 \pm 0.38$ & $2.25 \pm 0.50$ & $34.07 \pm 10.70$ \\
Average maximum EQE $(\%)$ & $0.03 \pm 0.01$ & $0.03 \pm 0.01$ & $0.02 \pm 0.004$ & $(1.5 \pm 1.0) \times 10^{-5}$
\end{tabular}

An elastomer long known for its excellent gas impermeability - butyl rubber - is reinvented for use in stretchable electronics to protect sensitive device materials and extend the lifetimes of stretchable devices. A new transparent butyl rubber formulation is reported, and its use as stretchable gas barrier for materials and devices sensitive to oxygen and moisture, such as organic semiconductors and light emitting devices, is demonstrated.

Keyword stretchable electronics, elastomers, gas barriers, butyl rubber, organic electronics

Akhil Vohra, Heather L. Filiatrault, Stanley D. Amyotte, R. Stephen Carmichael, Natalie D. Suhan, Conrad Siegers, Lorenzo Ferrari, Gregory J. E. Davidson, and Tricia Breen Carmichael*

\section{Reinventing Butyl Rubber for Stretchable Electronics}

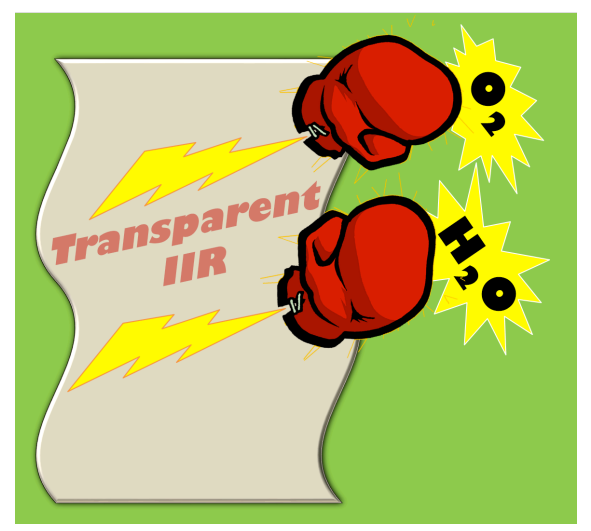




\section{WILEY-VCH}

Cover art submitted for consideration (image credit: Sara Mechael)

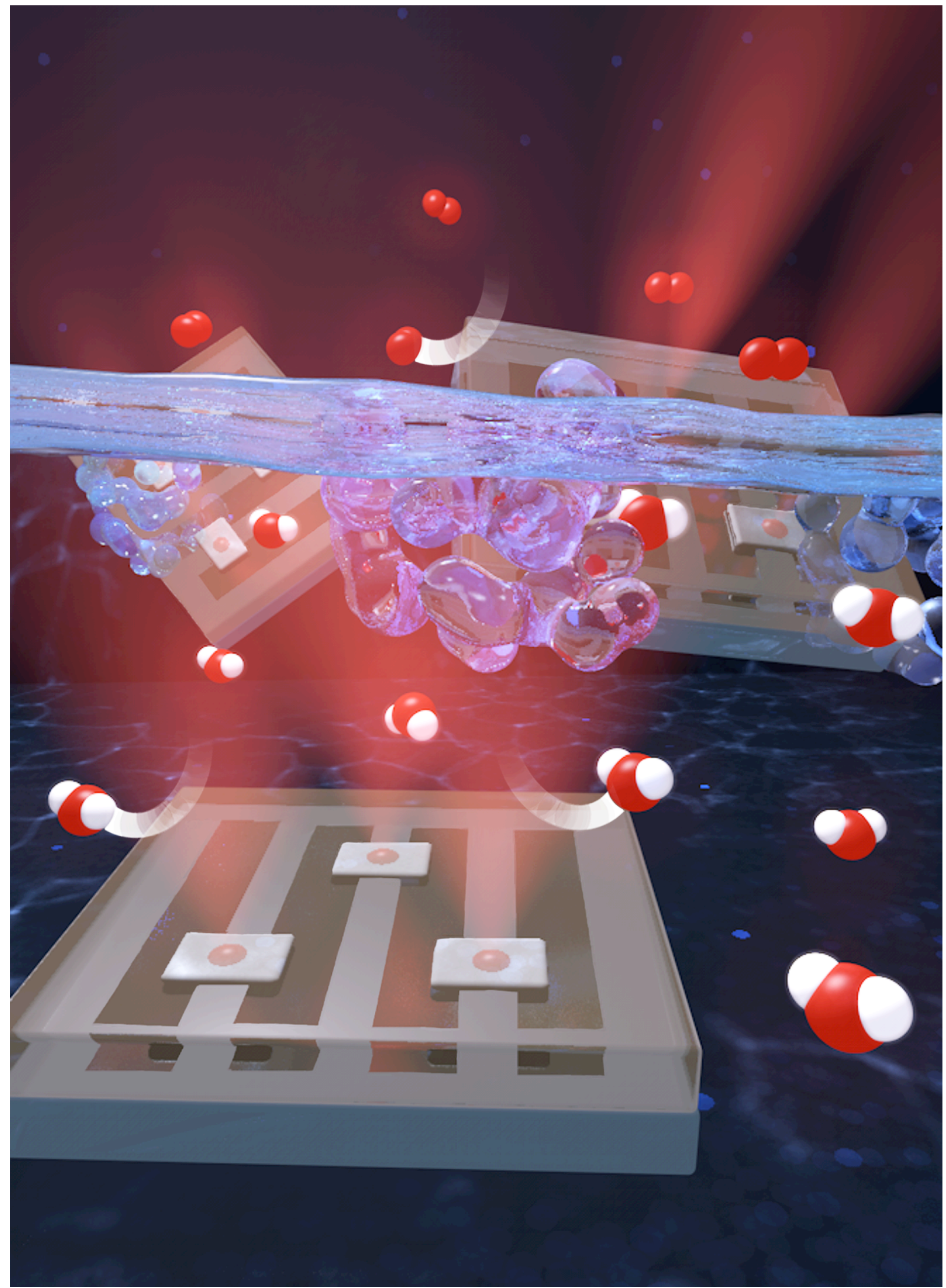

